Pobrane z czasopisma Annales I - Philosophy and Sociology http://philosophia.annales.umcs.pl Data: 26/04/2023 11:51:56

DOI: $10.17951 / i .2018 .43 .1 .175-191$

\begin{tabular}{c}
\hline A N N A LES \\
UNIVERSITATIS M A R I A E C URIE-SK Ł ODOWSKA \\
LOL B I N - P OL ON I A \\
SECTIO I
\end{tabular}

ZUZANNA TEPER-SOLARZ

ORCID ID: https://orcid.org/0000-0002-8742-7167

Uniwersytet Śląski

\title{
Echa technologii rozbrzmiewające w świecie ciszy
}

Technologies Echoing in the World of Silence

\section{WPROWADZENIE}

Co dokładnie dzieje się, gdy technologie komunikacyjne zabierają głos w świecie ciszy? Czy głusi są beneficjentami czy raczej może ofiarami wynalazków służących komunikacji międzyludzkiej? Aby odpowiedzieć na te pytania, autorka naszkicuje obraz społeczności Głuchych ${ }^{1}$, który jest niezbędnym tłem do podjęcia rozważań w przypadku tej i każdej innej tematyki związanej z tym środowiskiem. Świat Głuchych nie tylko różni się od świata, w którym przyszło nam na co dzień funkcjonować - jest on również zupełnie inny od społecznych wyobrażeń na jego temat $^{2}$. Opierają się one na stereotypach, które funkcjonują w świecie słyszących od pokoleń i utrwaliły obraz głuchego jako innego, niepełnosprawnego, infantylnego, aspołecznego, impulsywnego i naiwnego. Aktywnymi współtwórcami społecznych mitów są eksperci, którzy reprezentując medyczny pogląd na głuchotę, zredukowali wizerunek niesłyszących do ich ograniczeń ${ }^{3}$. H.L. Lane zauważa, że „Stykając się ze specyficznym językiem, kulturą i historią społeczności głuchych, słyszący

1 Pisownia słowa „głuchy” i jego odmian występuje w artykule w dwóch wersjach: $\mathrm{z}$ wielkiej i małej litery. Gdy autorka opisuje świat Głuchych i osoby deklarujące przynależność do niego, wówczas posługuje się wielką literą. Gdy wspomina o procesach, które dotyczą osób niesłyszących, bez względu na to, czy identyfikują się ze światem Głuchych czy nie, posługuję się małą literą.

2 Z. Teper-Solarz, Gtusi - na marginesie ,świata styszacych”, „Uniwersyteckie Czasopismo Socjologiczne. Academic Journal of Sociology" 2016, nr 14(1), s. 37-45.

3 H.L. Lane, Maska Dobroczynności. Deprecjacja społeczności głuchych, Warszawa 1996, s. $25,40-41,58-63$. 
profesjonaliści widzą jedynie niefunkcjonujące uszy i niekwestionowaną, wręcz rozpaczliwą potrzebę ich usług"4.

Opozycję dla perspektywy medycznej tworzą rzecznicy społecznego modelu ujmowania głuchoty. Autorka przyjrzy się Głuchym z tej perspektywy, by wyjaśnić specyfikę świata, który jest przedmiotem ich przeżyć. Dlaczego technologie informacyjne odgrywają tak ważną rolę w funkcjonowaniu poszczególnych jednostek i całego środowiska niesłyszących? Jak rozwój technologii komunikacyjnych splótł się z losem społeczności głuchych w przeszłości nam dalszej i bliższej? Co wiąże historię wykluczenia i emancypacji Głuchych z historią przeobrażeń tych technologii? Jak najnowsze wynalazki wpływają na życie współczesnych głuchych? Co sprawia, że potencjał, jaki ze sobą niosą, zmienia się w realne zagrożenie dla dalszego istnienia kultury Głuchych? Dla słyszących odpowiedzi na te pytania nie są oczywiste, podobnie jak przeważająca część tego, co dotyczy świata Głuchych. To czyni tę tematykę szczególnie interesującą.

Inspiracją do podjęcia tego tematu były opinie osób Głuchych, które autorka zgromadziła, realizując badania na potrzeby rozprawy doktorskiej. Kwestia technologii nie była przewodnim wątkiem wywiadów, nie stanowiła również wątku pobocznego. Wypłynęła ,przy okazji” poruszania innych tematów. Mówienie o niej jak o efekcie ubocznym badań byłoby jednak umniejszaniem jej wagi. Biorąc pod uwagę, że stała się inspiracją do ciekawych rozważań, należy o niej pisać raczej jako o wartości dodanej.

\section{DWA ŚWIATY - WYZNACZANIE GRANIC}

Wśród grup należących do statystycznej kategorii niepełnosprawnych osoby niesłyszące wyróżnia fakt tworzenia przez część z nich prawdziwej społeczności. Jej członkowie mówią o sobie Głusi - przez duże G, by podkreślić swoją przynależność do tej grupy ${ }^{6}$. Jest to dla nich powód do dumy, w przeciwieństwie do bycia „niesłyszącym”, „głuchoniemym” czy „osobą z uszkodzonym słuchem”.

4 Ibidem, s. 58.

5 Badania zostały zrealizowane metodą jakościową z wykorzystaniem technik Indywidulanego Wywiadu Pogłębionego (8 IDI) oraz Zogniskowanego Wywiadu Grupowego (6 mikrogrup FOKUSOWYCH) w 2016 r. Próba badawcza była wybrana w oparciu o zasady celowego, teoretycznego doboru w pierwszym etapie badań, zaś w kolejnych z wykorzystaniem teoretycznego pobierania próbek.

6 Z. Teper-Solarz, Wzrost mobilności a integracja spoleczna i aktywizacja zawodowa osób niestyszących - za kulisami innowacyjnego projektu testującego PI-MIGACZ wspierającego gluchych w uzyskaniu prawa jazdy, [w:] U. Bartnikowska, A. Żyta, S. Przybyliński (red.), Inkluzja - marginalizacja - wykluczenie a jakość życia osób z niepetnosprawnościa. Wyzwania współczesności, Olsztyn 2016, s. 178-179. 
Pobrane z czasopisma Annales I - Philosophy and Sociology http://philosophia.annales.umcs.pl Data: 26/04/2023 11:51:56

Określenia te mają negatywne konotacje i tworzą zafałszowany obraz głuchych, ponieważ podkreślają brak, skupiają się na różnicy i odstępstwie od normy. Tymczasem w oczach Głuchych ubytek słuchu to nie ułomność tylko cecha, która czyni ich wyjątkowymi. Głusi nie uważają się za osoby niepełnosprawne, wymagające leczenia, lecz za członków mniejszości językowo-kulturowej’. Społeczność ta ma pełną upadków i wzlotów historię, hołduje swoim bohaterom, nie zapomina krzywd wrogom oraz podziela wspólne symbole (motyl, kolor turkusowy). Poza tym posiada strukturę (z hierarchią i kryteriami przynależności), normy i wartości (egalitaryzm, kolektywizm, posiadanie głuchych dzieci, małżonków i przodków), wspólne wzory zachowań (utrzymanie kontaktu wzrokowego, rytuał powitania i pożegnania, nadawanie imion-znaków, wytrwałość w oczekiwaniu na kontakt, dzielenie się informacjami) i bogatą twórczość (teatr, poezja, malarstwo, fotografia, swoisty humor) ${ }^{8}$.

Świat Głuchych, czyli EYETH (w przeciwieństwie do zamieszkałej przez słyszących EARTH) ${ }^{9}$, powstał w odpowiedzi na wykluczenie głuchych z obszarów zarezerwowanych dla słyszących. Jedynie w nim czują się równi - mogą być sobą, nie tracąc przy tym poczucia bezpieczeństwa. Jak wskazuje O. Sacks:

Może dojść do sytuacji, w której niesłyszący będą czuli się zepchnięci na margines, izolowani, dyskryminowani. Jako antidotum na ów stan rzeczy niesłyszący tworzą swój świat, w którym czują się dobrze, który jest ich schronieniem i obroną przed nieakceptującym ich światem zewnętrznym ${ }^{10}$.

Podstawowym budulcem kultury Głuchych i skupionej wokół niej społeczności jest unikalny język, który Głusi stworzyli w ramach wzajemnych interakcji ${ }^{11}$. Wokół języka migowego, podobnie jak wokół niesłyszących, narosło wiele stereotypów. Język migowy, co zostało udowodnione przez lingwistów, jest prawdziwym

7 H.L. Lane, op. cit., s. 24, 26-27, 38-40; M. Sak, Ksztatcenie gluchych w szkołach masowych $i$ w klasach mieszanych z innymi niepetnosprawnościami, [w:] M. Sak (red.), Edukacja gluchych, Warszawa 2014, s. 76; T.K. Holcomb, Introduction to American Deaf Culture, New York 2009, s. 243-265.

8 B. Marganiec, Kultura Gtuchych, [w:] M. Świdziński (red.), Sytuacja osób głuchych w Polsce. Raport zespołu ds. g/Gluchych przy Rzeczniku Praw Obywatelskich, Warszawa 2014, s. 144-146; C.A. Padden, T.L. Humphries, Inside Deaf Culture, Cambridge 2006, s. 176; H.L. Lane, op. cit., s. 24; T.K. Holcomb, op. cit., s. 195-207; U. Bartnikowska, Sytuacja społeczna i rodzinna styszacych dzieci niestyszacych rodziców, Toruń 2010, s. 65-68.

9 EARTH to po polsku ZIEMIA. Trzy pierwsze litery wyrazu „Ziemia” odczytane samodzielnie („EAR”) oznaczają po angielsku UCHO. EARTH (Ziemia) zamieszkała jest przez „ludzi ucha”. EYETH (świat Głuchych) zamieszkały jest przez „ludzi oka” (EYE to po polsku OKO). Określenie zostało użyte w filmie dokumentalnym Through Deaf Eyes ukazującym 200 lat historii społeczności Głuchych w Ameryce.

10 O. Sacks, Zobaczyć głos, Warszawa 2011, s. 193.

11 B. Marganiec, op. cit., s. 137. 
językiem, który „w niczym nie ustępuje mowie, pozwalając na przekazywanie zarówno treści bardzo konkretnych, jak i poezji [...], często przewyższa nawet język mówiony pod względem łatwości, z jaką umożliwia wyrażanie owych treści" ${ }^{\prime 2}$. Jest to język o charakterze wizualno-przestrzennym. Posiada odmienną od języków fonicznych strukturę gramatyczną i składnię zdań ${ }^{13}$. Nie jest językiem uniwersalnym. Głusi zamieszkujący różne kraje posługują się innymi językami migowymi, w których występują dialekty i gwary. Z punktu widzenia problematyki podjętej w niniejszym artykule najważniejszy jest fakt, że dla osób, które urodziły się głuche lub utraciły słuch w okresie prelingwalnym, język migowy jest jedynym, który mogą przyswoić w sposób naturalny, w którym „dzieci głuche mają szansę zacząć mówić same z siebie"14. Język ojczysty jest dla nich jak język obcy i ,powinno się go nauczać jako języka obcego z wykorzystaniem narzędzi glottodydaktycznych [...]"15.

Problemy z komunikacją językową w świecie zdominowanym przez głos są głównym czynnikiem marginalizacji głuchych ${ }^{16}$. Niski poziom kompetencji językowych, zarówno w języku migowym, jak i ojczystym ${ }^{17}$, będący konsekwencją niedostosowania systemu edukacji do potrzeb i możliwości osób niesłyszących ${ }^{18}$, to bariera uniemożliwiająca sprawne porozumiewanie się, wymianę informacji, ekspresję uczuć i poznawanie otaczającego świata ${ }^{19}$. „Próżnia komunikacyjna” ogranicza potencjał rozwojowy niesłyszących, jest początkiem ,spirali strat”, prowadzi do wielowymiarowej deprywacji w praktycznie wszystkich przejawach życia społecznego ${ }^{20}$.

12 O. Sacks, op. cit., s. 43.

13 H.L. Lane, op. cit., s. 34-35.

14 M. Dunaj, W stronę edukacji dwujęzycznej dzieci głuchych w Polsce. Co wiemy/czego nie wiemy? Co należy zrobić?, Łódź 2016, s. 12-13.

15 M. Januszewicz, M. Jura, J. Kowal, Każdy ma prawo do nauki. Prawo gluchych do dostępu do języka i edukacji, [w:] M. Sak (red.), op. cit., s. 9-11.

16 O. Sacks, op. cit., s. 97.

17 M. Czajkowska-Kisil, A. Siepkowska, M. Sak, Edukacja gluchych w Polsce, [w:] M. Świdziński (red.), op. cit., s. 21, 24-25.

18 B. Wiśniewska, Dzieci z wada stuchu - specjalne potrzeby edukacyjne, [w:] E. Woźnicka (red.), Tożsamość społeczno-kulturowa głuchych, Łódź 2007, s. 124; H.L. Lane, op. cit., s. 44, 173-177; J. Kowal, Nowe spojrzenia-język polski jako obcy w kulturze i edukacji Gtuchych. Gtusi i ich języki obce, [w:] E. Woźnicka (red.), op. cit., s. 105; M. Czajkowska-Kisil, A. Siepkowska, M. Sak, op. cit., s. 24; M. Januszewicz, M. Jura, J. Kowal, op. cit., s. 8, 12-13; M. Sak, op. cit., s. 72-74; P. Tomaszewski, Funkcjonowanie poznawcze i językowe u dzieci głuchych, [w:] M. Sak (red.), op. cit., s. 31.

19 B. Wawrzyniak-Chrzanowska, Świat pełen znaczeń-osoby niestyszace jako twórcy i odbiorcy przekazów kulturowych, [w:] E. Woźnicka (red.), op. cit., s. 198; M. Dunaj, W stronę edukacji dwujęzycznej dzieci..., s. 17.

20 O. Sacks, op. cit., s. 102; U. Bartnikowska, op. cit., s. 52. 
Pobrane z czasopisma Annales I - Philosophy and Sociology http://philosophia.annales.umcs.pl Data: 26/04/2023 11:51:56

Echa technologii rozbrzmiewające w świecie ciszy

179

Dalsze konsekwencje obejmują niższą jakość i efektywność edukacji oraz kontaktów społecznych [...], dziecko niesłyszące przeżywające wiele frustracji, niezrozumienia, izolacji, wykluczenia będzie narażone na doznawanie pewnych strat dotyczących funkcjonowania psychicznego [...], może ucierpieć również sfera zawodowa jego funkcjonowania [...], a wraz z nią sfera ekonomiczna $[\ldots]$ i życie kulturalne $[\ldots]^{21}$.

Bez względu na to, czy osoby niesłyszące identyfikują się ze światem Głuchych czy nie, doświadczają tych samych problemów wynikających z funkcjonowania w świecie zdominowanym i zaprojektowanym przez słyszących, posługujących się stereotypowym obrazem głuchoty. Uświadomienie sobie problemów głuchych $\mathrm{z}$ komunikacją językową, w świecie funkcjonującym w oparciu o przekaz foniczny, pozwala zrozumieć, jak znaczący wpływ technologie komunikacyjne mogą wywierać na ich życie.

\section{PRZESZŁOŚĆ - USZCZELNIANIE GRANIC}

Zarówno historia wykluczenia, jak i emancypacji społeczności zbudowanych na bazie języków migowych są związane z pojawieniem się nowych technologii komunikacyjnych. O ile rozwój tych opartych o wizualne i dotykowe bodźce, bazujące na zmyśle wzroku i dotyku (pismo, druk, telegraf, nieme kino), nie wykluczał głuchych z głównego obiegu informacji, o tyle doprowadziło do tego wynalezienie telefonu ${ }^{22}$. Wcześniej, jak argumentuje M. Zdrodowska, „Głusi, jeśli tylko posiedli zdolność pisania i czytania, mogli w pełni partycypować w kreowanej przez technologie sferze informacyjnej"23. Dzięki upowszechnieniu nowej technologii słyszący zyskują możliwość komunikowania się na odległość w czasie rzeczywistym, głusi z kolei zostają wykluczeni z „oficjalnych obiegów kulturowych i komunikacyjnych" 24 , są odcięci od nietradycyjnych miejsc pracy i pozbawieni dostępu do nowych usług ${ }^{25}$. Był to początek końca rozkwitającej od 100 lat w szkołach dla niesłyszących kultury Głuchych (tzw. złoty wiek głuchoty) ${ }^{26}$. Mimo że telefon był jedynie jednym z wielu czynników, które doprowadziły do tej sytuacji, to jego twórca bywa obciążany odpowiedzialnością za taki rozwój wypadków. Upowszechnienie telefonu pokrywa się bowiem z okresem wzmożonej dyskryminacji niesłyszących przez środowisko oralistów oraz ruch eugeniczny,

${ }^{21}$ U. Bartnikowska, op. cit., s. 52.

22 M. Zdrodowska, Gtusi, telefony i cyborgi. Alternatywne opowieści o technologii, [w:] M. Sak (ed.), Deaf Studies w Polsce, t. 1, Łódź 2014, s. 32-33.

23 Ibidem, s. 32.

24 Ibidem.

25 Ibidem, s. 35.

26 O. Sacks, op. cit., s. 44, 48-49. 
Pobrane z czasopisma Annales I - Philosophy and Sociology http://philosophia.annales.umcs.pl Data: 26/04/2023 11:51:56

do których aktywnych działaczy zaliczał się A.G. Bell. W pamięci słyszących pozostaje on wynalazcą i filantropem. Dla Głuchych jest jednak antybohaterem. Sprzeciwiał się m.in. zawieraniu związków małżeńskich przez niesłyszących i ich samoorganizowaniu się, a także wykorzystywaniu języka migowego w edukacji i komunikacji głuchych ${ }^{27}$. Reorganizacja szkolnictwa w oparciu o doktrynę oralizmu, którą pod hasłem zapobiegania izolacji niesłyszących usankcjonował z grupą audystów w 1880 r. podczas Kongresu w Mediolanie, doprowadziła do katastrofy w systemie oświaty głuchych. „Oralizm oraz wyeliminowanie języka migowego ze szkół spowodowały znaczny spadek poziomu wykształcenia głuchej młodzieży, a w wielu przypadkach przyczyniły się do pojawienia się problemu analfabetyzmu wśród niesłyszących" ${ }^{28}$. Miało to daleko idące konsekwencje dla całej społeczności. Rozpoczęło też wieloletni okres deprecjonowania niesłyszących oraz języka i kultury Głuchych ${ }^{29}$.

Na zmianę przyszło głuchym czekać ponad 100 lat. Jej źródeł nie należy upatrywać w uchwalonej w 1934 r. ustawie komunikacyjnej (jedynie na papierze gwarantowała obywatelom USA równy dostęp do usług telekomunikacyjnych), lecz w wynalezieniu nowej technologii komunikacyjnej. W połowie lat 60. XX w. R. Weitbrecht, głuchy fizyk, astronom i inżynier elektroniki, skonstruował urządzenie łączące cechy maszyny do pisania i telefonu, które nam, współczesnym, przywodzi na myśl SMS-a ${ }^{30}$. Technologia ta, określana na zachodzie mianem TDD (telecomunication device for the deaf) i TTY (teletypewriter), w Polsce znana jako tekstofon ${ }^{31}$, dała głuchym pierwszą możliwość symultanicznej komunikacji na odległość w czasie rzeczy wistym. TDD był istotnym czynnikiem wzmacniającym i przyspieszającym budzące się na przełomie lat 60. i 70., po prawie 10 dekadach uśpienia, dążenia wolnościowe Głuchych ${ }^{32}$. „Wynalazek ten stał się istotnym elementem funkcjonowania niesłyszących, wprowadzającym po raz pierwszy w tkankę ich społeczności układ informacyjny, który pozwalał na synchroniczną, a nie wymagającą kontaktu bezpośredniego komunikację"333. Pomógł on zjednoczyć się rozproszonym grupom Głuchych i przekazywać informacje na bieżąco. Można więc powiedzieć, że te same mechanizmy, które uruchomiły proces społecznej marginalizacji niesłyszących, pozwoliły na rozkwit ruchów emancypacyjnych stawiających sobie za cel uwolnienie tej grupy spod jarzma słyszącej większości.

27 H.L. Lane, op. cit., s. 268-272; M. Zdrodowska, Gtusi, telefony i cyborgi..., s. 33-35.

28 O. Sacks, op. cit., s. 54.

29 H.L. Lane, op. cit., s. 148-156; O. Sacks, op. cit., s. 52-54.

30 H.L. Lane, R. Hoffmeister, B.J. Bahan, A Journey Into the Deaf-world, San Diego 1996, s. 360; M. Zdrodowska, Gtusi, telefony i cyborgi..., s. 35-36.

31 B. Szczepankowski, Niestyszacy - głusi-głuchoniemi, Warszawa 1999, s. 340.

32 M. Zdrodowska, Gtusi, telefony i cyborgi..., s. 35-36.

33 Ibidem, s. 36. 
Pobrane z czasopisma Annales I - Philosophy and Sociology http://philosophia.annales.umcs.pl Data: 26/04/2023 11:51:56

\section{INTERNET - OTWARCIE GRANIC}

O tym, jakie znaczenie w funkcjonowaniu grup marginalizowanych ma Internet, pisze K. Doktorowicz: „Potencjał demokratyczny i wolnościowy nowych mediów sprzyja zmianom politycznym, społecznym oraz komunikacji i ekspansji środowisk społecznych, politycznych oraz grup etnicznych pozbawionych wcześniej możliwości ekspresji swojej tożsamości" ${ }^{34}$. W życiu głuchych może on odgrywać istotniejszą rolę niż w przypadku pozostałych grup, które zostały wykluczone z głównego nurtu narracji. Jako technologia, która wykorzystuje oparte na tekście i obrazie przekazy, wydaje się być stworzony specjalnie w odpowiedzi na ich potrzeby. Swoiste cechy Internetu to aprzestrzenność (brak ograniczeń terytorialnych), asynchroniczność ${ }^{35}$ (komunikacja nie musi zachodzić w czasie rzeczywistym), acielesność (koncentracja na przekazie, a nie na nadawcy) i astygmatyczność (gwarancja anonimowości) ${ }^{36}$. Internet likwiduje zatem bariery, na jakie głusi napotykają w tradycyjnej komunikacji w aspekcie technicznym, praktycznym i psychologicznym. Ograniczeni głównie do aktów komunikacji bezpośredniej, mają szansę wzmocnić więzy rodzinne i towarzyskie. „Przestrzeń wirtualna przejęła funkcję podtrzymywania obecności [...], zmienia zasięg kontaktów [...]. Osoby głuche znacznie częściej mogą utrzymywać znajomości z innymi głuchymi znajdującymi się poza zasięgiem dostępności fizycznej ich klubu" ${ }^{37}$.

Internet nie tylko sprawia, że głusi mają szansę wydostać się z „próżni komunikacyjnej”. Pozwala im też pokonać bariery w dostępie do informacji, ograniczające możliwość pełnego uczestnictwa w życiu społecznym. „Ponadnarodowe interakcje głuchych sprzyjają rozprzestrzenianiu dyskursu na temat tożsamości głuchych, ich języka i kultury, zwiększają poziom świadomości głuchych" ${ }^{38}$. Internet jest więc miejscem ekspresji kultury Głuchych, wzbogacania, unifikacji i upowszechniania języka migowego oraz poszukiwania korzeni i tworzenia nowej tożsamości. To przestrzeń integracji niesłyszących z całego świata oraz

34 K. Doktorowicz, Tożsamość w epoce Internetu i globalnych sieci, [w:] K. Doktorowicz (red.), Tożsamość w wieku informacji. Media. Internet. Kino, Katowice 2015, s. 9, 14, 16; M. Zdrodowska, Strategie sieciowe grup wykluczonych, [w:] A. M. Klonkowska, M. Szulc (red.), Społecznie wykluczeni: niewygodni, nienormatywni, nieprzystosowani, nieadekwatni, Gdańsk 2013, s. 61, 63.

35 W przypadku Głuchych należałoby położyć nacisk na drugą stronę medalu, czyli synchroniczność Internetu.

36 Z. Rykiel, J. Kinal, Nowa tożsamość i nowa komunikacja?, [w:] Z. Rykiel, J. Kinal (red.), Tożsamości wirtualne i komunikacja w przestrzeni społecznej Internetu, Rzeszów 2013, s. 144.

37 M. Dunaj, Poza przymusem piśmienności - internetowe strategie w kulturze gluchych, [w:] Z. Rykiel, J. Kinal (red.), op. cit., s. 77.

38 D. A.M. De Clerc, An Era of Epistemological Equity, [w:] P. V. Paul, D.F. Moores (eds.), Deaf Epistemologies: Multiple Perspectives on the Acquisition of Knowledge, Washington 2012, s. 27. 
Pobrane z czasopisma Annales I - Philosophy and Sociology http://philosophia.annales.umcs.pl Data: 26/04/2023 11:51:56

budowania poczucia przynależności do sieciowej społeczności głuchych, kreującej dyskurs związany z głuchotą, zabierającej głos w nurtujących ją kwestiach. Poza tym stanowi forum walki Głuchych o ich prawa, jest medium służącym do obalania społecznych mitów, przestrzenią zredefiniowania swojej pozycji w społeczeństwie ${ }^{39}$. „Tak zwana czwarta władza kształtuje nie tylko opinię, ale dzięki swej niekwestionowanej sile oddziaływania także politykę społeczną"40. Zyskanie tożsamości i poczucia przynależności do ponadnarodowej społeczności oznacza nie tylko wzrost samoświadomości, ale również posiadanie wyższej samooceny i pewności siebie. Ponadto daje poczucie większej kontroli nad swoim życiem i samodzielności, a tym samym większej motywacji do działania. Przytaczając wyniki badań przeprowadzonych na 35 tys. użytkownikach sieci, M. Castells podkreśla, że „korzystanie z internetu wzmacnia respondentów: zwiększa ich poczucie bezpieczeństwa, wolności osobistej i wpływu na własne życie, a są to uczucia, które wpływają korzystnie na ich stan psychiczny"41.

Użytkowanie Internetu przez głuchych niesie jednak za sobą zagrożenia. Są to typowe niebezpieczeństwa, na które narażeni są także słyszący członkowie wirtualnej społeczności, oraz dodatkowe, wynikające ze specyfiki ich środowiska. Przedstawione poniżej wątki zostały zaczerpnięte z wypowiedzi Głuchych rozmówczyń i rozmówców biorących udział w realizowanych przez autorkę indywidualnych i grupowych wywiadach. Nie oznacza to, że nie dostrzegają oni jasnych stron Internetu. W wymiarze indywidualnym doceniają przede wszystkim wygodę, którą daje im korzystanie z wirtualnej sieci. Natomiast mówiąc o zmianach, które zaszły w dobie Internetu, szczególnie w wymiarze kolektywnym, częściej wskazywali na jego negatywne następstwa. Ich zdaniem niszczy on w kulturze Głuchych to, co w niej swoiste. Wzmacnia też negatywne wzory zachowań, których do tej pory, z uwagi na ograniczenia przestrzenne, nie odczuwano tak dotkliwie. Choć Internet zwiększa zasięg kontaktów, ich jakość pozostawia wiele do życzenia, a poziom zażyłości wirtualnych znajomości jest niższy niż w przypadku relacji tworzonych „twarzą w twarz”. W ich mniemaniu słowo przekazane przez Internet

39 Ibidem, s. 26-28; I.W. Leigh, A Lens on Deaf Identities, Perspectives on Deafness, New York 2009, DOI: https://doi.org/10.1093/acprof:oso/9780195320664.001.0001, s. 148; K. Doktorowicz, op. cit., s. 16, 26; L.W. Zacher, Utechnicznienie człowieka i marketyzacja jego działalności a kultura przyszłości, „Zeszyty Naukowe Politechniki Śląskiej, Seria: Organizacja i Zarządzanie” 2015, z. 85, s. 617-641; M. Castells, Siła tożsamości, Warszawa 2008, s. 22-28; M. Zdrodowska, Strategie sieciowe..., s. 65-66.

40 D. Podgórska-Jachnik, Deprecjacja osób z niepetnosprawnościa w dyskursie publicznym za pośrednictwem mediów, [w:] Z. Gajdzica (red.), Człowiek z niepełnosprawnościa w rezerwacie przestrzeni publicznej, Kraków 2013, s. 76-78.

${ }_{41}$ D. A.M. De Clerc, op. cit., s. 26-28; M. Castells, Sieci oburzenia i nadziei: ruchy społeczne w erze internetu, Warszawa 2013, s. 224. 
Pobrane z czasopisma Annales I - Philosophy and Sociology http://philosophia.annales.umcs.pl Data: 26/04/2023 11:51:56

nie niesie odpowiedzialności i nie zobowiązuje tak, jak przyrzeczenie czy deklaracja złożone podczas tradycyjnej rozmowy. Internet sprzyja kłamstwom i ułatwia rozprzestrzenianie plotek oraz rozleniwia. Sprawił, że Głusi, którzy cenili sobie bezpośrednie relacje, zamknęli się w domach. Poza tym ma negatywny wpływ na relacje międzypokoleniowe, prowadzi do zaniku bezpośredniej transmisji kultury, wiedzy i doświadczeń. Młodzi wybierają komfort komunikacji wirtualnej, a tradycyjne miejsca międzypokoleniowych spotkań Głuchych powoli pustoszeją wraz ze śmiercią ich kolejnych bywalców. Internet nie tylko osłabia tradycyjne więzi wewnątrz społeczności Głuchych - oddala ich dodatkowo od świata słyszących, gdyż demotywuje do nauki pisania i czytania oraz utrzymywania kontaktów ze słyszącymi. Z raportu G. Valentine, T. Skelton i P. Levy wynika, że to nie brak potrzeby, lecz obawy wynikające z niskich kompetencji językowych oraz wzajemnych uprzedzeń prowadzą do unikania spotkań międzykulturowych. Internet tworzy również nowe, ,wirtualne” obszary wykluczenia wewnątrz mocno już zhierarchizowanej społeczności Głuchych, zwiększając lukę międzypokoleniową. Dzieli Głuchych na wykluczonych i włączonych w życie społeczeństwa informacyjnego oraz wirtualnej społeczności Głuchych. Dzieje się tak głównie z powodu barier, na jakie napotykają głusi użytkownicy sieci. Najważniejsze z nich to bariera: mentalna (technofobia, strach przed nieznanym, brak zaufania, motywacji i potrzeby, pasywność, niska samoocena), kompetencyjna (brak umiejętności obsługi komputera, programów i Internetu, niskie kompetencje językowe, brak szkoleń i materiałów edukacyjnych w języku migowym) oraz ekonomiczna (brak środków na zakup sprzętu, łącza, oprogramowania i udział w szkoleniach) ${ }^{42}$.

Przytoczona poniżej rozmowa odnosi się do wielu wskazanych wyżej negatywnie ocenianych obszarów wpływu Internetu na Głuchych:

B: ale lepiej wtedy czy teraz?

1: dawniej... teraz siedzenie tylko w domu przy komputerze... kiedyś były spotkania na żywo... teraz lepiej w domu wygodniej siedzieć... komputer wystarczy... wcześniej tego nie było... były spotkania głuchych... a teraz nie, nie bo zajęty, zajęty

3: od kiedy głusi mają podłączenie do komputerów wszyscy wolą siedzieć w domu

B: a kluby... młodzi przychodzą?

1: kluby... starzy

2: są młodzi ale wszyscy siedzą w domu

3: i to jest właśnie taki upadek pokolenia... nie można dzieci nauczyć bycia Głuchym... nie ma Głuchych bo wszyscy się pochowali do domów

1: plotek nie było... telefon służy do plotek... teraz gorzej... jeżeli nie ma telefonu... nie ma Internetu to nie ma też plotek

42 G. Valentine, T. Skelton, P. Levy, The Role of the Internet in D/deaf People's Inclusion in the Information Society, www.sheffield.ac.uk/polopoly_fs/1.268538!/file/d-deaf_report.pdf [dostęp: 07.04.2018]. 
2: Internet wyciąga tajemnice... od razu wygada tajemnice (wszyscy potakują)

3: słyszący mówią, że nie wierzą... głusi mówią że jeden głos i cała polska wie ${ }^{43}$

Co sprzyja wykorzystywaniu Internetu przez głuchych? Fakt, że ani ponadnarodowe zrozumienie, ani ponadnarodowa komunikacja nie sprawiają im problemów. Bez względu na to, czy identyfikują się ze światem Głuchych czy nie, łączy ich wspólnota doświadczeń. Ich biografie mają podobny przebieg, napotykają na te same bariery w każdej społeczności słyszących. Głusi z różnych krajów mają ze sobą więcej wspólnego niż słyszący i głusi z jednego kraju ${ }^{44}$.

Badania pokazują, że międzynarodowa komunikacja nie sprawia głuchym problemów, adaptują swoje własne języki, używają międzynarodowego języka migowego lub uczą się lokalnych języków migowych. Korzystają z globalizacji, z zasobów technologicznych i ekonomicznych, część z przedstawicieli młodego pokolenia rozwija ponadnarodowe głuche tożsamości (transnational deaf identities $)^{45}$.

Mimo że badania wskazują, iż głusi i słabosłyszący internauci to jedne $\mathrm{z}$ aktywniejszych społeczności mniejszościowych $\mathrm{w}$ sieci ${ }^{46}$, to większość z nich nie wykorzystuje pełnego potencjału Internetu, używając go głównie w celach komunikacyjnych. Potrzeba kontaktu i dostępu do informacji jest dla głuchych niezwykle istotna, a dzięki Internetowi mogą zaspokoić ją w prosty i niewymagający specjalistycznych kompetencji sposób.

\section{IMPLANTY - PRZEKRACZANIE GRANIC}

Implanty to kolejna technologia, która na pierwszy rzut oka jest dla niesłyszących szansą na lepsze życie, której żaden głuchy nie powinien zaprzepaścić. W rzeczywistości kwestia implantowania, w szczególności dzieci, wywołuje ogromne poruszenie w środowisku Głuchych, wzbudza niezwykle silne i najczęściej negatywne emocje. Aby zrozumieć ten fenomen, należy zacząć od wyjaśnienia, czym jest wspomniana technologia.

Implant ślimakowy to elektroniczne urządzenie zmieniające fale dźwiękowe w impulsy elektryczne, które za pomocą wszczepionego przewodu są przekazywane do ucha środkowego, gdzie za sprawą umieszczonej w ślimaku elektrody

43 Źródło: badania własne, fragment badania FOKUS, listopad 2016.

44 Zob. M. M. McKee, P.C. Hauser, Juggling Two Worlds, [w:] P.V. Paul, D. F. Moores (eds.), op. cit., s. 51.

45 D.A.M. De Clerc, op. cit., s. 27.

46 I.W. Leigh, op. cit., s. 148; M. Dunaj, Poza przymusem piśmienności..., s. 76; M. Zdrodowska, Strategie sieciowe..., s. 66. 
Pobrane z czasopisma Annales I - Philosophy and Sociology http://philosophia.annales.umcs.pl Data: 26/04/2023 11:51:56

nerw słuchowy podlega stymulacji i są wywoływane wrażenia słuchowe ${ }^{47}$. Jest to technologia, które pozwala głuchym słyszeć.

Dlaczego implanty wzbudzają w świecie Głuchych tyle kontrowersji? Uczestnicy badań autorki byli ich zdecydowanymi przeciwnikami. Większość przytoczonych przez nich argumentów znajduje potwierdzenie w literaturze. Opisane zostały poniżej: od tych najbardziej racjonalnych, po najbardziej abstrakcyjne dla słyszących, a najistotniejsze z punktu widzenia Głuchych.

Argumenty natury medycznej można podzielić na dwie grupy. Pierwsze są związane z wszczepieniem implantu, co wymaga przeprowadzenia operacji chirurgicznej przy ogólnym znieczuleniu, która wiąże się z hospitalizacją i ryzykiem powikłań. Efektem ubocznym bywa utrata resztek słuchu oraz zaburzenia smaku. „Natomiast sama operacja stanowi swego rodzaju psychiczne zagrożenie dla rozwoju dziecka [...], jest ona traumatycznym doświadczeniem. Dziecko reaguje zarówno na narkozę, ból pooperacyjny, jak i hospitalizację" ${ }^{\text {48 }}$. Drugie zaś są związane z negatywnymi odczuciami i ograniczeniami użytkowników tego urządzenia. Skarżą się oni na powracające bóle i zawroty głowy oraz szumy uszne, nie mogą być resuscytowani, nie można ich poddawać badaniu z użyciem rezonansu magnetycznego, a urazy głowy mogą być tragiczne w skutkach ${ }^{49}$.

Kolejne zarzuty mają charakter pragmatyczny. Głusi narzekają na brak skuteczności tych urządzeń. Słuch uzyskiwany dzięki wszczepowi nie jest naturalny, a jedynie zbliżony jakościowo do słuchu fizjologicznego. „W wyniku rozbieżności pomiędzy naturalnym mechanizmem słyszenia a mechanizmem słyszenia z implantem otrzymujemy poprzez implant dźwięk dość trudny w interpretacji, a czasem i do zlokalizowania [...]"50. Uzyskanie zadowalających efektów jest odsunięte w czasie nawet o kilka lat od operacji z uwagi na konieczność przystosowania mózgu do interpretacji informacji akustycznych. Mówienie i rozumienie słów wymaga wieloletniej rehabilitacji mowy i treningu słuchu, których rezultat nie zawsze przynosi zamierzone efekty ${ }^{51}$. Respondenci wskazali również na ograniczenia związane z uprawianiem niektórych sportów (nurkowanie) oraz utrudnienia dotyczące podróżowania samolotem (przy bramkach, podczas startu i lądowania).

47 B. Szczepankowski, op. cit., s. 330; H.L. Lane, op. cit., s. 273-276; P. Hepp, Świat w moich dtoniach, życie bez stuchu i wzroku, Katowice 2008, s. 222.

48 U. Bartnikowska, op. cit., s. 34.

49 C.A. Padden, T.L. Humphries, op. cit., s. 166; H.L. Lane, op. cit., s. 21-22, 272-273; U. Bartnikowska, op. cit., s. 33-34.

50 H.L. Lane, op. cit., s. 276.

${ }_{51}$ Ibidem, s. 276; H.L. Lane, R. Hoffmeister, B.J. Bahan, op. cit., s. 400; M. Czajkowska-Kisil, Gtusi, ich język i kultura-zarys problematyki, [w:] P. Rutkowski, S. Łozińska (red.), Lingwistyka przestrzeni i ruchu. Komunikacja migowa a metody korpusowe, Warszawa 2014, s. 20; P. Hepp, op. cit., s. 223. 
Zrozumiałe są głosy dotyczące kwestii finansowych, czyli wysokich kosztów wszczepienia, wymiany urządzeń i rehabilitacji ${ }^{52}$, oraz fakt odebrania statusu osoby niepełnosprawnej, a co za tym idzie utraty prawa do renty. Słyszącym znacznie trudniej jest rozumieć argumenty natury społecznej i politycznej, na które Głusi kładą szczególny nacisk. Jak słusznie zauważa U. Bartnikowska: „Technika nie rozwiązuje wszystkich problemów, które w dużej mierze tkwią nie w samej wadzie słuchu, ale w społecznym odbiorze odmienności człowieka" ${ }^{53}$. Implant nie czyni z osoby głuchej osoby „,normalnej” z punktu widzenia słyszących. W ich oczach nadal pozostaje ona głuchym, tyle że zaimplantowanym. Natomiast dla przedstawicieli społeczności Głuchych nie jest już „wystarczająco głucha” (not Deaf enough) ${ }^{54}$. Otrzymuje wówczas status outsidera: „Nie jest ani w świecie Głuchych, ani w świecie słyszących, jest w świecie cyborgów"55. Taka sytuacja może prowadzić do podwójnego wykluczenia i napiętnowania. Osoby te mogą mieć trudności ze znalezieniem swojego miejsca na ziemi. Narażone są na problem „bezdomności kulturowej” ${ }^{56}$. Zdaniem H.L. Lane wśród zaimplantowanych dzieci „Mogą wyłonić się trudności związane z przystosowaniem emocjonalnym, z identyfikacją, a nawet ze zdrowiem psychicznym [...]"57.

W opinii wielu Głuchych implanty stanowią zagrożenie dla ich świata i kultury. Budzą one skojarzenia z niebezpiecznym eksperymentem. Te głosy brzmią szczególnie donośnie w przypadku dyskursu dotyczącego implantacji dzieci. „Ponad 90\% dzieci głuchych rodzi się rodzicom słyszącym, którzy się tego nie spodziewali, nie mieli kontaktu ze społecznością Głuchych i językiem migowym, nie mają też żadnej wiedzy na ten temat"s8. Decyzja o operacji najczęściej jest podejmowana w imieniu nieletnich przez rodziców, którzy są zagubieni, przepełnieni strachem i niepewnością. „Słyszący rodzice [...] zwykle bezkrytycznie przyjmują ten proponowany im model głuchoty, zwracając się o pomoc do instytucji reprezentujących w społeczeństwie dziedzinę medycyny [...]"59, tym samym bezkrytycznie przyjmując argumenty popierające implantację. Podejmowane pod presją czasu decyzje są

52 H.L. Lane, op. cit., s. 260.

53 U. Bartnikowska, op. cit., s. 39.

54 Hasło drugiego protestu studentów Uniwersytetu Galladetta, którzy odrzucili kandydaturę dr Jane Farnandes na rektora ich uczelni z uwagi na to, iż nie wzrastała w środowisku i języku Głuchych od dziecka (zob. T.K. Holcomb, op. cit., s. 274-277).

55 Argument jednego z bohaterów nominowanego do Oskara dokumentu Sound and fury, który przedstawia istotę sporu związanego z implantowaniem.

56 H.L. Lane, op. cit., s. 23, 285-287; H.L. Lane, R. Hoffmeister, B. J. Bahan, op. cit., s. 389392; M. Czajkowska-Kisil, op. cit., s. 21; T.K. Holcomb, op. cit., s. 77-78.

57 H.L. Lane, op. cit., s. 23.

58 U. Bartnikowska, op. cit., s. 51.

59 H.L. Lane, op. cit., s. 261. 
nieodwracalne. Powrót do świata Głuchych bywa niemożliwy, gdy kilkanaście lat później ich dzieci odkryją swoje korzenie. Niektóre z programów terapii zakazują bowiem używania języka migowego podczas rehabilitacji, co ma być warunkiem osiągnięcia pełnych korzyści zaimplantowania ${ }^{60}$. „Opóźnienie wczesnego kontaktu z językiem migowym dla dzieci głuchych jest tak samo ryzykowne, jak opóźnienie dostępu do mowy wśród dzieci słyszących"61. W rzeczywistości może to oznaczać opóźnienie dostępu dziecka do języka w ogóle, co - jak podkreśla M. Czajkowska-Kisil - „negatywnie wpłynie na jego rozwój poznawczy i społeczny”².

Chcąc zrozumieć te skrajne głosy, pamiętajmy, że głusi nie uważają się za osoby chore i w związku z tym wymagające uzdrowienia. Ich spontaniczna odpowiedź na pytanie, czy woleliby, aby urodziło im się dziecko głuche czy słyszące, zazwyczaj brzmi: „Nieważne. Ważne, żeby było zdrowe”63. Zainteresowanie implantowaniem wśród Głuchych dorosłych jest niskie również dlatego, że ich sytuacja nie jest źródłem cierpienia, gdyż „trzeba czegoś doświadczyć i to stracić, żeby potem móc tęsknić” ${ }^{64}$. Jeżeli spojrzymy na głuchych z kulturowej perspektywy, kwestia implantowania staje się problematyczna z punktu widzenia etyki ${ }^{65}$. Takie podejście dobrze obrazuje wypowiedź wielopokoleniowo Głuchej rozmówczyni, która oddaje emocjonalny klimat panujący wokół problematyki implantów:

ABSOLUTNIE... zakaz... może powstać później choroba różna w głowie... może coś się stać, przewrócić... nie dziękuję, dużo dzieci umarło... a potem rośnie, zwariować można... ja nie chcę... chcę manifest żeby była likwidacja implantów... głusi są źli, nie chcą... po co?... lepiej aparat, tyle wystarczy... ja nie jestem robotem żeby mi robili implant!... tak wygląda robot... i się śmieją... dokuczają głusi... robot... co jakiś czas trzeba operację a przy aparacie nie ma problemu... po co implant?... często boli głowa przez implant... to rodzice decydują... dziecko głuche małe... a później nawet renty nie ma... nie płacą... po co?... nie chcę... ja jestem zdrowa... Głucha... mam ręce... cała jestem zdrowa! ${ }^{66}$

Technologia implantowania, mimo sprzeciwów środowisk Głuchych na całym świecie, rozwijała się sukcesywnie od lat 60 . XX w. Jak pokazują badania, efekty implantowania bywają różne, a ich poziom to wypadkowa indywidualnych zmiennych, takich jak czynniki anatomiczne, fizjologiczne, psychologiczne i socjologiczne. Technologia wciąż się rozwija, minimalizowane są medyczne ryzyka

60 C.A. Padden, T.L. Humphries, op. cit., s. 168-169; H.L. Lane, R. Hoffmeister, B.J. Bahan, op. cit., s. 371-373, 402-403; M. Czajkowska-Kisil, op. cit., s. 20-21; T.K. Holcomb, op. cit., s. 78.

${ }_{61}$ H.L. Lane, R. Hoffmeister, B.J. Bahan, op. cit., s. 373.

62 M. Czajkowska-Kisil, op. cit., s. 20.

63 Źródło: badania własne, FOKUSY (listopad 2016) i IDI (luty 2016).

64 P. Hepp, op. cit., s. 225.

65 Ch.J. Heuer, BUG: Deaf Identity and Internal Revolution, Washington 2007, s. 98-99; H.L. Lane, R. Hoffmeister, B.J. Bahan, op. cit., s. 361; O. Sacks, op. cit., s. 26; P. Hepp, op. cit., s. 252.

66 Źródło: badania własne, fragment badania IDI, luty 2016. 
Pobrane z czasopisma Annales I - Philosophy and Sociology http://philosophia.annales.umcs.pl Data: 26/04/2023 11:51:56

związane z wszczepem. Aktualnie w dyskursie związanym z implantami kładzie się nacisk na zagadnienia języka i kultury. Głusi chcą pogodzić dobro dzieci (otwarcie na możliwości, jakie daje implant) z dobrem ich środowiska (zachowanie transmisji kultury). Wymaga to rozwijania dwukulturowości i dwujęzyczności ${ }^{67}$. „Wszechobecne przekonanie o konieczności wyboru pomiędzy implantem a Głuchotą staje się sprawą dyskusyjną [...], a wiarygodność mieszanego podejścia ma potwierdzenie w wynikach aktualnych badań" ${ }^{68}$. Decyzja o wszczepie nie musi być kwestią wyboru między życiem w jednym lub drugim świecie, może stać się szansą na życie w dwóch światach jednocześnie.

\section{PRZYSZŁOŚĆ - ŚWIAT BEZ GRANIC?}

Nie ma dobrej odpowiedzi na pytanie o to, czy nowoczesne technologie komunikacyjne są dla głuchych większą szansą czy zagrożeniem. Każda technologia może zarazem służyć celom dobrym i złym, a jej ocena musi być dokonywana z uwzględnieniem kontekstu społecznego i jednostkowego, w odniesieniu do jej użytkowników i odbiorców. Dodatkowo zmiany to procesy nieprzewidywalne. Możliwości kontrolowania i sterowania nimi zmniejszają się wraz ze wzrostem złożoności świata. Wynalazki często żyją swoim życiem. Burzą jedne granice, tworząc nowe obszary wykluczenia.

Aktualnie Głusi stoją wobec nowego wyzwania - inżynierii genetycznej i czynionych w jej ramach prób zidentyfikowania ,genu głuchoty” w celu jej wyeliminowania. Potencjalnie stanowi ona największe z zagrożeń technologicznych, jakim przyszło stawić im czoła. Pojawiają się głosy, że Głusi stoją w obliczu walki o przetrwanie. Ich szanse na wygraną osłabia brak wewnętrznej zgody środowiska odnośnie do kwestii przynależności do ich świata osób „niewystarczająco głuchych” ${ }^{\circ}$. Dopóki wszyscy nie przemówią jednym głosem, szanse na życie w świecie bez granic maleją, gdyż „Na każdą osobę odrzucaną z powodu bycia niewystarczająco głuchą przypada znacznie więcej odrzucanych za to, że są zbyt głuche"70.

67 D. Podgórska-Jachnik, Gtusi. Emancypacje, Łódź 2013, s. 117, 144-145; H.L. Lane, R. Hoffmeister, B.J. Bahan, op. cit., 386-407; I. W. Leigh, op. cit., s. 155-159; P.E. Spencer, M. Marschark, Coachelar Implants - Issues and Implications, [w:] M. Marschark, P.E. Spencer (eds.), Oxford Handbook of Deaf Studies, Language and Education, Oxford-New York 2003, s. 434-442.

${ }^{68}$ I.W. Leigh, op. cit., 157.

69 C.A. Padden, T.L. Humphries, op. cit., 163-166; Ch.J. Heuer, op. cit., 199; T.K. Holcomb, op. cit., 267-268, 274, 276; M. Miller, Deaf Worldviews, Views of the Deaf World, and the role of Deaf Children of Hearing Parents in Creating a Deaf Epistemology, [w:] P. V. Paul, D.F. Moores (eds.), op. cit., s. 151-152; I. Parasnis, Diversity and Deaf Identity, [w:] P.V. Paul, D. F. Moores (eds.), op. cit., s. 71.

70 Ch.J. Heuer, op. cit., s. 223. 


\section{BIBLIOGR AFIA}

Bartnikowska U., Sytuacja społeczna i rodzinna styszacych dzieci niestyszacych rodziców, Toruń 2010.

Castells M., Sieci oburzenia i nadziei: ruchy społeczne w erze internetu, Warszawa 2013.

Castells M., Siła tożsamości, Warszawa 2008.

Czajkowska-Kisil M., Gtusi, ich język i kultura - zarys problematyki, [w:] P. Rutkowski, S. Łozińska (red.), Lingwistyka przestrzeni i ruchu. Komunikacja migowa a metody korpusowe, Warszawa 2014.

Czajkowska-Kisil M., Siepkowska A., Sak M., Edukacja głuchych w Polsce, [w:] M. Świdziński (red.), Sytuacja osób gluchych w Polsce. Raport zespołu ds. g/Gtuchych przy Rzeczniku Praw Obywatelskich, Warszawa 2014.

De Clerc D. A.M., An Era of Epistemological Equity, [w:] P. V. Paul, D. F. Moores (eds.), Deaf Epistemologies: Multiple Perspectives on the Acquisition of Knowledge, Washington 2012.

Doktorowicz K., Tożsamość w epoce Internetu i globalnych sieci, [w:] K. Doktorowicz (red.), Tożsamość w wieku informacji. Media. Internet. Kino, Katowice 2015.

Dunaj M., Poza przymusem piśmienności - internetowe strategie w kulturze gluchych, [w:] Z. Rykiel, J. Kinal (red.), Tożsamości wirtualne i komunikacja w przestrzeni społecznej Internetu, Rzeszów 2013.

Dunaj M., W stronę edukacji dwujęzycznej dzieci głuchych w Polsce. Co wiemy/czego nie wiemy? Co należy zrobić?, Łódź 2016.

Hepp P., Świat w moich dłoniach, życie bez stuchu i wzroku, Katowice 2008.

Heuer Ch.J., BUG: Deaf Identity and Internal Revolution, Washington 2007.

Holcomb T.K., Introduction to American Deaf Culture, New York 2009.

Januszewicz M., Jura M., Kowal J., Każdy ma prawo do nauki. Prawo gtuchych do dostepu do języka i edukacji, [w:] M. Sak (red.), Edukacja głuchych, Warszawa 2014.

Kowal J., Nowe spojrzenia - język polski jako obcy w kulturze i edukacji Gtuchych. Gtusi i ich języki obce, [w:] E. Woźnicka (red.), Tożsamość społeczno-kulturowa głuchych, Łódź 2007.

Lane H.L., Maska Dobroczynności. Deprecjacja społeczności głuchych, Warszawa 1996.

Lane H.L., Hoffmeister R., Bahan B.J., A Journey Into the Deaf-world, San Diego 1996.

Leigh I.W., A Lens on Deaf Identities, Perspectives on Deafness, New York 2009, DOI: https://doi.org/10.1093/acprof:oso/9780195320664.001.0001.

Marganiec B., Kultura Gtuchych, [w:] M. Świdziński (red.), Sytuacja osób głuchych w Polsce. Raport zespołu ds. g/Gluchych przy Rzeczniku Praw Obywatelskich, Warszawa 2014.

McKee M.M., Hauser P.C., Juggling Two Worlds, [w:] P.V. Paul, D.F. Moores (eds.), Deaf Epistemologies: Multiple Perspectives on the Acquisition of Knowledge, Washington 2012.

Miller M., Deaf Worldviews, Views of the Deaf World, and the Role of Deaf Children of Hearing Parents in Creating a Deaf Epistemology, [w:] P. V. Paul, D.F. Moores (eds.), Deaf Epistemologies: Multiple Perspectives on the Acquisition of Knowledge, Washington 2012.

Padden C. A., Humphries T.L., Inside Deaf Culture, Cambridge 2006.

Parasnis I., Diversity and Deaf Identity, [w:] P. V. Paul, D.F. Moores (eds.), Deaf Epistemologies: Multiple Perspectives on the Acquisition of Knowledge, Washington 2012.

Podgórska-Jachnik D., Deprecjacja osób z niepetnosprawnością w dyskursie publicznym za pośrednictwem mediów, [w:] Z. Gajdzica (red.), Człowiek z niepełnosprawnościq w rezerwacie przestrzeni publicznej, Kraków 2013.

Podgórska-Jachnik D., Głusi. Emancypacje, Łódź 2013.

Rykiel Z., Kinal J., Nowa tożsamość i nowa komunikacja?, [w:] Z. Rykiel, J. Kinal (red.), Tożsamości wirtualne i komunikacja w przestrzeni społecznej Internetu, Rzeszów 2013. 
Sacks O., Zobaczyć głos, Warszawa 2011.

Sak M., Ksztatcenie gtuchych $w$ szkołach masowych $i$ w klasach mieszanych $z$ innymi niepetnosprawnościami, [w:] M. Sak (red.), Edukacja głuchych, Warszawa 2014.

Spencer P.E., Marschark M., Coachelar Implants - Issues and Implications, [w:] M. Marschark, P.E. Spencer (eds.), Oxford Handbook of Deaf Studies, Language and Education, Oxford-New York 2003.

Szczepankowski B., Niestyszacy - głusi-głuchoniemi, Warszawa 1999.

Teper-Solarz Z., Gtusi - na marginesie „świata styszacych”, „Uniwersyteckie Czasopismo Socjologiczne. Academic Journal of Sociology” 2016, nr 14(1).

Teper-Solarz Z., Wzrost mobilności a integracja społeczna i aktywizacja zawodowa osób niestyszacych - za kulisami innowacyjnego projektu testujacego PI-MIGACZ wspierajacego głuchych w uzyskaniu prawa jazdy, [w:] U. Bartnikowska, A. Żyta, S. Przybyliński (red.), Inkluzja-marginalizacja-wykluczenie a jakość życia osób z niepetnosprawnościa. Wyzwania wspótczesności, Olsztyn 2016.

Tomaszewski P., Funkcjonowanie poznawcze i językowe u dzieci głuchych, [w:] M. Sak (red.), Edukacja gluchych, Warszawa 2014.

Valentine G., Skelton T., Levy P., The Role of the Internet in D/deaf People's Inclusion in the Information Society, www.sheffield.ac.uk/polopoly_fs/1.268538!/file/d-deaf_report.pdf [dostęp: 07.04.2018].

Wawrzyniak-Chrzanowska B., Świat pełen znaczeń - osoby niestyszace jako twórcy i odbiorcy przekazów kulturowych, [w:] E. Woźnicka (red.), Tożsamość społeczno-kulturowa głuchych, Łódź 2007.

Wiśniewska B., Dzieci z wada słuchu - specjalne potrzeby edukacyjne, [w:] E. Woźnicka (red.), Tożsamość społeczno-kulturowa głuchych, Łódź 2007.

Zacher L.W., Utechnicznienie człowieka i marketyzacja jego działalności a kultura przyszłości, „Zeszyty Naukowe Politechniki Śląskiej, Seria: Organizacja i Zarządzanie” 2015, z. 85.

Zdrodowska M., Glusi, telefony i cyborgi. Alternatywne opowieści o technologii, [w:] M. Sak (ed.), Deaf Studies w Polsce, t. 1, Łódź 2014.

Zdrodowska M., Strategie sieciowe grup wykluczonych, [w:] A.M. Klonkowska, M. Szulc (red.), Społecznie wykluczeni: niewygodni, nienormatywni, nieprzystosowani, nieadekwatni, Gdańsk 2013.

\section{SUMMARY}

The article is an attempt to show the transformations of the deaf and the Deaf communities in the context of the communication technologies changes taking place between the last two decades of the $19^{\text {th }}$ century and first two decades of the $21^{\text {st }}$ century. The analysis of the history of the Deaf minority, show that the nature of technology is neither good nor bad. That inventions that have a beneficial effect on one group may have negative connotations to the members of the other. The Deaf world and the hearing world have always been divided by the boundaries of communication abilities. Looking back in time for further communications revolutions, we can see what changes of those borders were ongoing under their influence. Their lines are transformed with the next innovations: tightening up, moving, blurring.

Keywords: the d/Deaf; communication technologies; change 
Pobrane z czasopisma Annales I - Philosophy and Sociology http://philosophia.annales.umcs.pl Data: 26/04/2023 11:51:56

\section{STRESZCZENIE}

Niniejszy artykuł stanowi próbę ukazania przeobrażeń, którym podlegają osoby niesłyszące i społeczności Głuchych na tle technologicznych zmian zachodzących w obszarze komunikacji w okresie od ostatnich dwóch dekad XIX w. po pierwsze dwie dekady XXI w. Analizując zarys dziejów niesłyszącej mniejszości, możemy się przekonać, że technologie z natury nie są ani dobre, ani złe, a wynalazki mające dobroczynny wpływ na jedne grupy, wśród członków innych grup mogą wywoływać negatywne skojarzenia. Świat Głuchych i świat słyszących zawsze oddzielała wyraźna granica wyznaczona przez możliwości komunikacyjne. Spoglądając z perspektywy czasu na kolejne rewolucje technologiczne w tym obszarze, można zaobserwować, jakim przemianom granice te ulegały pod ich wpływem. Wraz z kolejnymi innowacjami dochodzi do ich przeobrażeń: uszczelnienia, przesunięcia, zacierania.

Słowa kluczowe: g/Głusi; technologie komunikacyjne; zmiana 